\title{
Factors Affecting the Spread of Plum pox virus Strain M in Peach Orchards Subjected to Roguing in France
}

\author{
Sylvie Dallot, Tim Gottwald, Gérard Labonne, and Jean-Bernard Quiot
}

First and second authors: U.S. Department of Agriculture-Agricultural Research Service, U.S. Horticultural Research Laboratory, 2001 South Rock Road, Ft. Pierce, FL 34945; and third and fourth authors: UMR BGPI, Institut National de la Recherche Agronomique, CIRAD TA 41/K, Campus international de Baillarguet, 34398 Montpellier Cedex 5, France.

Current address of S. Dallot: UMR BGPI, Institut National de la Recherche Agronomique, CIRAD TA 41/K, Campus international de Baillarguet, 34398 Montpellier Cedex 5, France.

Accepted for publication 23 July 2004.

ABSTRACT

\begin{abstract}
Dallot, S., Gottwald, T., Labonne, G., and Quiot, J.-B. 2004. Factors affecting the spread of Plum pox virus strain $\mathrm{M}$ in peach orchards subjected to roguing in France. Phytopathology 94:1390-1398.

We evaluated the impact of roguing on the spread and persistence of the aggressive Plum pox virus strain M (PPV-M) in 19 peach orchard blocks in Southern France. During a 7- to 10-year period, orchards were visually inspected for PPV symptoms, and symptomatic trees were removed every year. Disease incidence was low in all orchards at disease discovery and was $<1 \%$ in 16 of the 19 orchard blocks. The spread of Sharka disease was limited in all 19 blocks, with an annual disease incidence between 2 and $6 \%$. However, new symptomatic trees were continuously detected, even after 7 to 10 years of uninterrupted control measures. An extended Cox model was developed to evaluate to what extent tree location, orchard characteristics, environment, and disease status within the vicinity influenced the risk of infection through time. Eleven variables with potential effect on tree survival (i.e., maintenance of a tree in a dis-
\end{abstract}

ease-free status through time) were selected from survey data and databases created using a geographical information system. Area of the orchard, density of planting, distance of a tree from the edge of the orchard block sharing a boundary with another diseased orchard, and distance to the nearest previously detected symptomatic tree had a significant effect on the risk for a tree to become infected through time. The combined results of this study suggest that new PPV-M infections within orchards subjected to roguing resulted from exogenous sources of inoculum, disease development of latent infected trees, as well as infected trees overlooked within the orchards during visual surveys. A revision of the survey and the roguing procedures used for more effective removal of potential sources of inoculum within the orchards and in the vicinity of the orchards would improve disease control suppression of PPV.

Additional keywords: disease eradication, survival analysis, virus epidemiology.
With increasing international trade and travel, the risk of introductions of plant pathogens and subsequent invasion of agroecosystems has increased dramatically over the last few decades, despite increasing awareness and controls at borders. Once a new plant pathogen is introduced, its eradication or containment to restricted cropping areas is often attempted to prevent or reduce its impact on the afflicted agricultural industry. Among various strategies, roguing (i.e., the removal of sources of infections) has often been implemented to control vector-borne virus diseases of perennial crops $(2,5,40,41)$. The success of such eradication and containment programs depends on the rapidity at which control measures are applied after the introduction of the threatening pathogen and on the level of knowledge and understanding of the ecology of the related disease, its characteristics of spread in space and time, and the availability of efficient detection and sampling methods (40).

Sharka disease, caused by Plum pox virus (PPV) is one of the most serious viral diseases of stone-fruit crops, including peach (Prunus persica L.), apricot (P. armeniaca L.), plums (P. domestica L. and $P$. salicina Lindl.) as well as sweet and sour cherries ( $P$. avium L. and $P$. cerasus L.) that may be systemically infected by a few unique PPV strains $(11,29,30)$. The virus is transmitted

Corresponding author: S. Dallot; E-mail address: dallot@ensam.inra.fr

Publication no. P-2004-1025-01R

This article is in the public domain and not copyrightable. It may be freely reprinted with customary crediting of the source. The American Phytopathological Society, 2004. by vegetative propagation and is spread by at least 20 different aphid species in a nonpersistent manner, allowing epidemics to develop rapidly $(4,23,24)$. Among the four identified groups of PPV, the PPV-D and PPV-M strains are the most prevalent and differ in disease severity among Prunus species, especially in their ability to infect peach trees via aphid transmission. Fastspreading outbreaks are mostly associated with the PPV-M strain $(13,31)$.

PPV is a good example of an invasive, fast-spreading plant pathogen on the worldwide scale. Since its discovery in Bulgaria in 1915, the disease has spread throughout Europe despite local control attempts and has been identified in the Middle East, in South America (Chile), as well as in the United States and Canada in $1999(25,28,33)$. In the United States, an eradication program is currently applied, based on the implementation of strict quarantine and removal procedures. Such a program has a good chance of success in the United States because disease introduction is recent, geographically limited, and only the PPV-D strain has been identified. In France, both PPV-D and PPV-M strains are present, but epidemics related to the PPV-M strain introduced in the mid1980s are the most problematic (31). A strict program to control the aggressive PPV-M strain has been in place since the early 1990s. This program is based on the complete removal of affected orchards when disease incidence is $>10$ to $20 \%$ or on the removal of only the symptomatic trees if incidence is $<10 \%$ and consequently when rates of disease progress are still limited. Such procedures, combined with strict quarantine procedures, the protection of nurseries, and the certification of virus-free material, have allowed the containment of the disease in limited areas 
where disease prevalence is generally low (35). However, continuous surveys and removals are still ongoing more than 10 years after the initial identification of this aggressive strain in France.

The evaluation of integrated control measures on disease spread is generally based on comparative epidemiology requiring welldesigned field experiments to ensure strict comparative measurements of relevant parameters of the pathosystem followed by univariate or multivariate analysis $(22,26)$. Explanatory variables of disease spread are generally elucidated from the analysis of disease progress curves by fitting well-described growth functions $(8,43)$. Survival analysis is a class of statistical methods especially designed to study the occurrence and the timing of events (such as infection) while allowing for censored observations (e.g., the event has not occurred for all individuals by the end of the study or its occurrence is not known) $(10,17,36)$. Both parametric and semiparametric approaches are used in survival analysis. The semiparametric Cox model is a particularly robust approach because a specific distribution does not need to be specified. Moreover, new extensions of the model allow for a variety of situations, including the analysis of correlated events and time-varying covariates (36). This approach is widely used in medical epidemiology (36) but very rarely in botanical epidemiology $(21,34)$. Scherm and Ojiambo (34) recently reviewed the principles of such methods and their applications in plant pathology.

The objectives of this study were to (i) describe and analyze Sharka disease spread within peach orchards of Southern France subjected to roguing and (ii) develop an exploratory approach using Cox modeling to identify which factors associated with diseased orchards and within the vicinity of diseased orchards influence the risk for the trees to become infected through time and, as a result, affect the persistence of the disease.

\section{MATERIALS AND METHODS}

Surveys for PPV and roguing. Surveys for Sharka infections due to the PPV-M strain are performed visually by specifically trained teams from the plant protection services ("Service de la Protection des Végétaux") and from professional organizations ("Fédération Régionale de Défense contre les Organismes Nuisibles"). Initial infection within each planting is confirmed via Double-antibody sandwich, enzyme-linked immunosorbent assay on a bulk sample of leaves collected from one to several symptomatic trees and the strain of PPV is characterized via polymerase chain reaction or western blot (6). Once the presence of the disease has been confirmed, all trees in each affected orchard are inspected individually two to three times each year during spring to early summer when symptoms are most easily observed. PPVsymptomatic trees are identified and removed shortly after their discovery.

Orchard blocks. Nineteen peach orchard blocks affected by the PPV-M strain were selected from survey databases (Table 1). Orchard blocks were characterized by a unique cultivar/year and density of planting combination, and all but one were physically separated from other peach blocks by one or several windbreaks. The selection of orchard blocks was based on various criteria, including (i) low disease incidence at first disease discovery, (ii) availability of records of multiple assessments over several years, and (iii) available information on orchard block characteristics and on disease status in the vicinity. These orchard blocks were surveyed during 7 to 10 consecutive years until blocks were either removed for other reasons than Sharka disease or until 2002 (end of data collection for this study). In all cases, identified PPVsymptomatic trees were removed each year.

These blocks were located in stone-fruit plantings of three regions of Southern France, five blocks in the Drôme region, six in the Gard region, and eight in the Pyrénées-Orientales region. Orchard blocks in the Pyrénées-Orientales region were located no further than $1.5 \mathrm{~km}$ from each other in a relatively heterogeneous landscape, which covered approximately $3.3 \mathrm{~km}^{2}$ and was characterized by clusters of peach orchards generally surrounded by vineyards. Selected blocks in the Drôme and Gard regions were part of the same commercial plantings and were located at a maximum distance of $800 \mathrm{~m}$ from each other. All orchards were irrigated and received standard commercial horticultural, disease, and insect management.

Variable selection. Eleven variables were selected from survey databases or collected using a geographical information system application constructed from aerial ortho-photography under Arcview 3.1 (Environmental Systems Research Institute, Redlands, CA). Selected variables used for further data analysis describe (i) individual trees within orchard blocks, (ii) various orchard characteristics, and (iii) the environment directly contiguous to the blocks. Their description and summary statistics are listed in Tables 2 and 3 .

Individual tree descriptors. For each surveyed orchard block, the number of symptomatic peach trees identified and removed each year was reported from the time of the first PPV detection. Annual maps indicating the location of all symptomatic and nonsymptomatic trees were also available for the entire survey period. The distance of each tree to the edge of the block directly

TABLE 1. Characteristics of the peach blocks surveyed for Plum pox virus strain M in Southern France

\begin{tabular}{|c|c|c|c|c|c|c|}
\hline Region & Block & Cultivar ${ }^{\mathrm{a}}$ & Year of planting & Survey period & Tree spacing $(\mathrm{m})^{\mathrm{b}}$ & Initial no. of trees \\
\hline \multirow[t]{7}{*}{ Pyrénées Orientales } & P1 & Gladys (P) & 1987 & 1994-2002 & $2 \times 5$ & 692 \\
\hline & P2 & Gladys (P) & 1990 & 1994-2001 & $2 \times 5$ & 1,471 \\
\hline & P3 & Spring Lady (P) & 1993 & 1994-2000 & $2.5 \times 5$ & 510 \\
\hline & P5 & O’Henry (P) & 1989 & 1994-2001 & $2 \times 5$ & 631 \\
\hline & P6 & Michelini (P) & 1989 & 1994-2001 & $2 \times 5$ & 535 \\
\hline & P7 & Vivian $(\mathrm{P})$ & 1984 & 1994-2000 & $3.5 \times 6$ & 1,023 \\
\hline & P8 & O’Henry (P) & 1980 & $1994-2000$ & $3 \times 6$ & 329 \\
\hline \multirow{4}{*}{ Gard } & G3 & Silver Late $(\mathrm{P})$ & 1988 & 1993-2002 & $3 \times 5.5$ & 1,099 \\
\hline & G4 & Lucie $(\mathrm{P})$ & 1988 & 1993-2002 & $2.5 \times 6$ & 583 \\
\hline & G5 & Red Robin (P) & 1982 & 1993-2002 & $4.5 \times 6$ & 503 \\
\hline & G6 & Summer Lady (P) & 1995 & $1997-2002$ & $3 \times 6$ & 655 \\
\hline \multirow[t]{2}{*}{ Drôme } & D1 & Aline $(\mathrm{P})$ & 1989 & 1993-2002 & $4 \times 5$ & 188 \\
\hline & D2 & Royal Glory (P) & 1989 & 1993-2001 & $3.2 \times 6$ & 161 \\
\hline
\end{tabular}

\footnotetext{
${ }^{a} \mathrm{P}$ and $\mathrm{N}$ indicate peach or nectarine cultivar, respectively.
}

${ }^{\mathrm{b}}$ Distance between trees within $\times$ across rows. 
adjacent to another diseased orchard (or the one with the highest disease incidence when several affected orchards were identified) was calculated (variable name: DINOC). The distances from all symptomatic and asymptomatic trees to the nearest previously detected symptomatic tree within the same block (DIST) were also computed for each year of survey and for each plot using the SPATSTAT version 1.3-2 and SPLANCS 2.01-9 libraries under the statistical package $\mathrm{R}$ version $1.7 .1(18,32)$. The nearestneighbor distances from newly infected trees to previously detected symptomatic ones were also pooled by year across all orchard blocks and parsed into contiguous 6-m (i.e., the greatest distance between immediately adjacent, across-row tree neighbors) distance classes.

Orchard block characteristics. Available data included size of the orchard blocks (in hectares), year of planting, tree spacing within and across rows, and cultivar. Summary information of the main characteristics of these blocks is presented in Table 1. From this first data set, other variables were determined including cultivar maturity (MAT) and density of planting in trees per hectare (DENS). Maturity was defined by three classes corresponding to three time periods when fruit reached maturity, each approximately 1 month in duration: the class "early" was attributed to the cultivars with maturity occurring before 15 July, the class "medium" was attributed to the cultivars with maturity occurring between 15 July and 15 August, and the class "late" was attributed to the cultivars with maturity occurring after 15 August. The dates of maturity of cultivars in Southern France were obtained from various technical reports (14).

Descriptors of orchard block vicinity. The presence of windbreaks surrounding the blocks, their number (NWIB) and their orientation relative to the dominant wind direction in the specific studied regions were noted. Information describing the immediate vicinity, i.e., the number of contiguous susceptible Prunus crops (RISK) and PPV-affected peach orchard blocks (INOC), was also collected. An isolation index (ISOL) was computed for each block, which summed the weight scores attributed to each windbreak, depending on its orientation relative to the dominant wind direction and the presence or absence of an exogenous source of PPV inoculum contiguous to this windbreak. The weight scores were calculated as follows: a value of 1 was given when a windbreak was parallel or oblique to the dominant wind direction and with no contiguous exogenous source of inoculum, 2 for a windbreak perpendicular to the dominant wind but with no contiguous exogenous inoculum source, 3 for a windbreak parallel or oblique to the wind direction but with a contiguous source of PPV inoculum, and 4 for a windbreak perpendicular to the dominant wind and with contiguous PPV inoculum sources. Due to incomplete data, information from greater distances (i.e., areas not directly contiguous to the studied orchard blocks) could not be used.

Survival analysis. Survival analysis methods were applied to investigate which factors relating to the blocks themselves or to their immediate vicinity significantly influenced the spread of PPV-M within the blocks (i.e., the risk for a tree to develop symp- toms of PPV through time). Analysis was performed using the Survival library version 2.9-10 under the statistical package R 1.7.1 (37). A large data set of 89,369 rows (yearly individual tree observations) and 12 columns (explanatory variables) was used for analysis.

An extended Cox model using a counting process approach was fitted to the data in order to incorporate the time-dependent covariate DIST (i.e., the repeated measurement over time of the distance of a tree to the previously detected, nearest symptomatic neighbor) (36). This semiparametric model specifies the hazard for an individual tree $i$ at time $t$ as $h_{i}(t)=h_{0}(t) \exp \left[\beta^{\prime} X_{i}(t)\right]$, in which $h_{0}(t)$ indicates an unspecified baseline hazard function, $X_{i}(t)$ indicates the vector of values at time $t$ of the time-dependent and time-independent covariates, and $\beta^{\prime}$ indicates the vector of associated coefficients that are estimated by partial likelihood (10).

The potential effect of a covariate is quantified via the hazard ratio (HR), expressed in terms of an exponential of the corresponding estimated $\beta$ coefficient for one unit change in the value of the given variable. An HR value of $1(\hat{\beta}=0)$ indicates no significant effect of the covariate tested. Trees within a single block (identified by the covariate BLOCK) were not independent because they shared identical characteristics (same cultivar, maturity, and age) and the disease status of one tree might have influenced the disease status of other trees within the blocks. The cluster(BLOCK) function of the Survival library was used, which identifies correlated observations within blocks and computes robust variance estimates of the $\beta$ parameters by grouped jackknife (marginal approach) (37). Tie events were handled using the Efron method of estimation rather than the exact method because the latter method was too computation-intensive for the large data set. The date of the beginning of risk was approximated to be the first year of survey for each of the blocks because the date of first disease introduction was not known and disease incidence was very low at disease discovery.

The selection of covariates in model development was performed following the recommendations of Hosmer and Lemeshow (17). Significance of each of the covariates was first

TABLE 3. Summary statistics for the categorical variables used in the Cox model to describe time to infection of trees by Plum pox virus strain $\mathrm{M}$ in peach orchards in Southern France

\begin{tabular}{lc}
\hline Categorical variable & Number of trees $n$ (proportion) \\
\hline MAT: maturity of cultivar ${ }^{\mathrm{a}}$ & \\
Late & $6,574(55.3 \%)$ \\
Medium & $2,602(21.9 \%)$ \\
Early & $2,705(22.8 \%)$ \\
PRUNUS & \\
Peach & $7,687(64.7 \%)$ \\
Nectarine & $4,194(35.3 \%)$ \\
\hline
\end{tabular}

a The class "early" was attributed to the cultivars with maturity occurring before 15 July, the class "medium" was attributed to cultivars with a maturity date between 15 July and 15 August, and the class late was attributed to cultivars with a maturity date after 15 August.

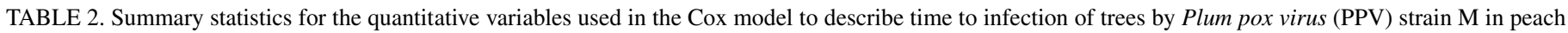
orchards in Southern France

\begin{tabular}{|c|c|c|}
\hline Quantitative variable & Units or scale & Median (range) \\
\hline AGE: age of trees at first PPV detection in an orchard block & Years & $6(1-15)$ \\
\hline AREA: physical area occupied by a block & Hectares & $1.36(0.22-2.30)$ \\
\hline DENS: density of planting & Trees/hectare & $606(370.3-1,000)$ \\
\hline NWIB: number of windbreaks & 0 to 4 & $2(0-3)$ \\
\hline ISOL: isolation index ${ }^{\mathrm{a}}$ & 0 to 13 & $3.5(0-8)$ \\
\hline RISK: number of contiguous Prunus blocks & 0 to 4 & $2.5(1-4)$ \\
\hline INOC: number of contiguous PPV-affected blocks & 0 to 4 & $2(0-3)$ \\
\hline DINOC: distance of a tree to the edge of the block closest to an identified exogenous source of inoculum & $\mathrm{m}$ & $48(2-168)$ \\
\hline DIST: nearest-neighbor distance to previously detected symptomatic trees (time-dependent covariate) & $\mathrm{m}$ & $12(2-209.58)$ \\
\hline
\end{tabular}

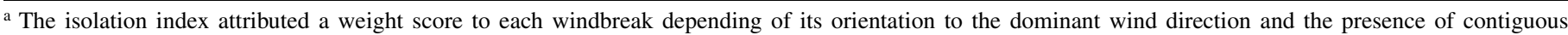
exogenous source of inoculum. 
evaluated by univariate Cox regression analysis. Covariates significant at $P=0.2$ were used for the development of the multivariate Cox model in a forward selection process. Significance of individual explanatory variables $(P=0.05)$ was assessed using the univariate Wald statistic, which follows a standard normal distribution and is given by $z=\hat{\beta} / \mathrm{SE}(\hat{\beta})$.

The effect of the added covariate on overall multivariate model significance was assessed using the multiple-variable Wald test
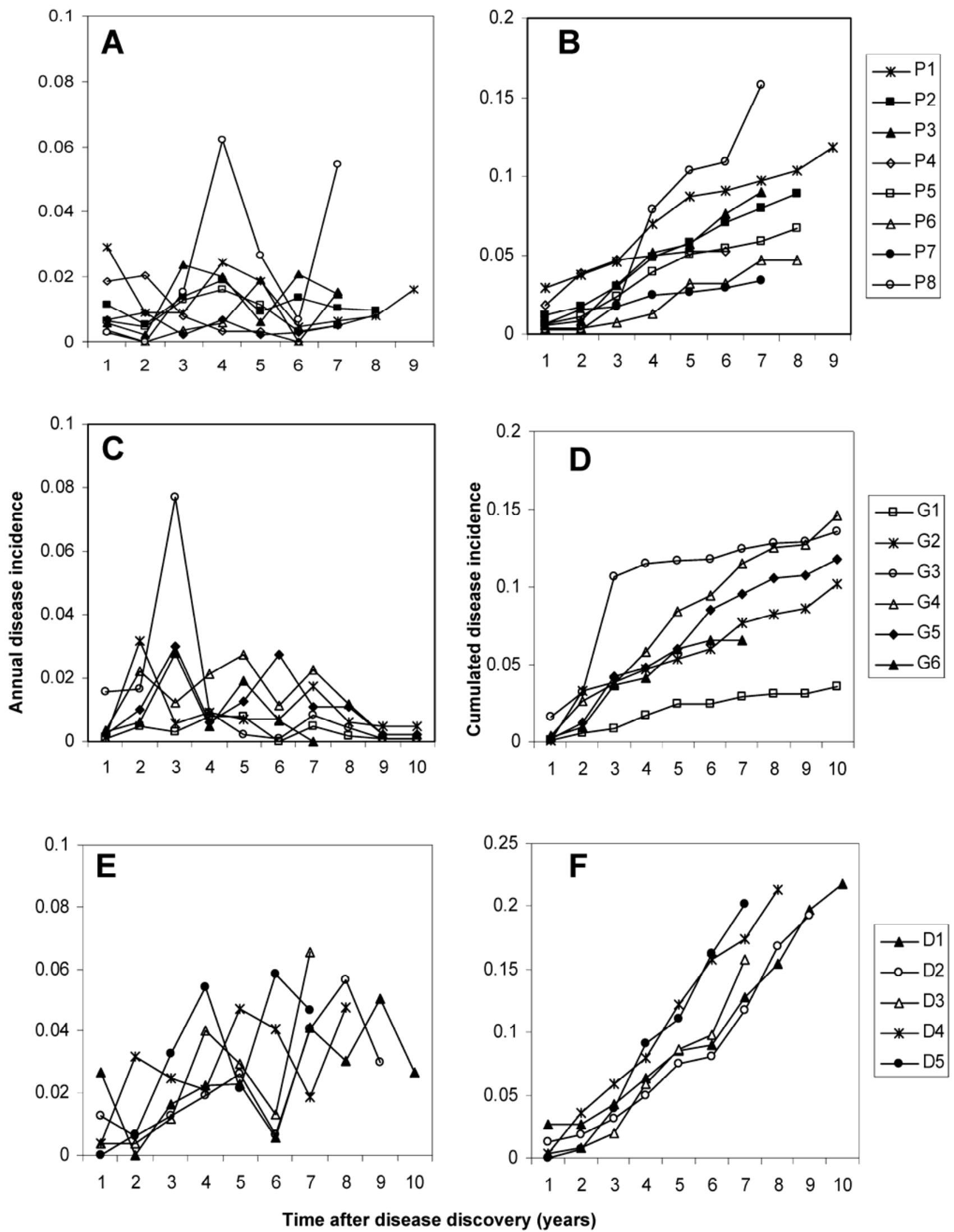

Fig. 1. A, C, and E, Annual disease incidence for the Pyrénées Orientales (PO), Gard (G), and Drôme (D) peach blocks infected by Plum pox virus strain M, respectively. B, D, and F, Cumulative disease incidence including rogued trees for PO, G, and D blocks, respectively. 
calculated for pairs of nested models that varied only in the inclusion of the covariate of interest. The Wald test was used instead of the usual likelihood-ratio test because of the use of robust variance estimation (36). The multivariable Wald test follows a $\chi^{2}$ distribution, and associated $P$ values were calculated using a number of degrees of freedom that was equal to the difference in the number of estimated parameters between the two compared models. Previous nonsignificant covariates were re-introduced one by one in the final model to verify that they had no significant effect.

Residuals for the functional form (linearity of $\hat{\beta}$ coefficients in the log hazard) were checked using plot functions provided in the Survival library following the recommendations of Therneau and Gambrsch (36). The assumption of time-independent $\hat{\beta}$ coefficients was checked by evaluating the plot of the scaled Schoenfeld residuals against a nonlinear scale of time with a spline smoother and by testing the correlation coefficient between transformed survival time and the scaled Schoenfeld residuals using the cox.zph function included in the Survival library, which allows for time-dependent covariates.

\section{RESULTS}

Annual and cumulative disease incidence. Disease incidence was very low at first assessment, suggesting that the PPV epidemic was at a very early stage of development (Fig. 1). It was $<0.01$ in 13 of the 19 orchard blocks and $<0.03$ in the remaining 6 blocks. The progression of the disease in these blocks remained very limited due to diseased tree removals. Annual disease incidence was low and varied through time, reaching 0.02 for the blocks of the Pyrénées-Orientales and Gard regions and 0.06 for the blocks of the Drôme region (Fig. 1A, C, and E). In this latter region, an increasing trend of annual disease incidence through time was observed. Higher disease incidence values were observed for the blocks P8 (0.06) and G3 (0.08), 4 and 3 years after disease discovery, respectively. The cumulative disease incidence after 7 to 10 years of survey was highly variable among plots, ranging from $<0.04$ (P6 and G1) to 0.22 (D1) (Fig. 1B, D, and F). More rapid disease increase occurred mostly in the blocks of the Drôme region, with a cumulative disease incidence close to 0.2 at the end of the survey period (Fig. 1F).

Extended Cox model. The model that best fit the data showed a significant influence of the following factors on the probability for a tree to remain asymptomatic for $t$ years: (i) the distance of a tree to the edge of a block contiguous to an exogenous source of inoculum (DINOC), (ii) the nearest-neighbor distance to previously detected symptomatic trees within blocks (DIST), (iii) the square of the area of the blocks $\left(\mathrm{AREA}^{2}\right)$, and (iv) the density of planting (DENS). Each of these factors was significant based

TABLE 4. Selection of covariates in an extended Cox survival model with potential effect on the risk for a tree to become infected through time by Plum pox virus strain $\mathrm{M}$ in peach orchards in Southern France

\begin{tabular}{lcc}
\hline Explanatory variable & Wald $\chi^{2 \mathrm{a}}$ & $P$ \\
\hline DINOC & 19.4 & $<0.0001$ \\
DIST & 44 & $<0.0001$ \\
AREA $^{2 b}$ & 4.01 & 0.045 \\
DENS & 4.01 & 0.045 \\
INOC & 2.78 & 0.095 \\
RISK & 0.46 & 0.497 \\
ISOL & 0.19 & 0.663 \\
NWIB & 0.17 & 0.680 \\
AGE & 0.04 & 0.84 \\
MAT & 2.44 & 0.295 \\
PRUNUS & 0.06 & 0.806 \\
\hline
\end{tabular}

a Results are for the multivariate Wald test for the introduction of each covariate one at a time. The covariates INOC, RISK, ISOL, NWIB, AGE, MAT, and PRUNUS were also nonsignificant in univariate analysis at $P=0.2$.

${ }^{b} \mathrm{AREA}^{2}$ is the square value of the covariate AREA and provided a more significant effect. on the results of univariate Wald tests, and each made a significant improvement to the full model based on multivariable Wald tests computed for nested models differing only by the covariate of interest (Table 4). None of the seven other variables tested were significant at $P=0.2$ based on univariate Wald tests, nor when they were reintroduced one-by-one in the model (Table 4). However, the variable INOC was close to the significance threshold in both the univariate $(P=0.27)$ and multivariate tests $(P=0.095)$.

The assumption of time independence of the $\hat{\beta}$ coefficients was verified only for the trees still at risk after the second year of survey. However, $\hat{\beta}$ coefficients of the model fitted to the reduced data set excluding the observations of the first 2 years were only slightly modified (less than $15 \%$ change), except for the coefficient associated with the covariate $\mathrm{AREA}^{2}$, indicating an even stronger risk of becoming PPV-symptomatic with decreasing block size (data not shown). No major changes were obtained when the two atypical blocks showing much higher disease incidence in a specific year (blocks T8 and G3) were excluded from the data set.

The risk of PPV infection through time under roguing decreased with increasing values of all of the significant covariates (Table 5). Based on the values of the estimated hazard ratio, an increase of $100 \mathrm{~m}$ from the edge of a block sharing a boundary with another PPV-affected orchard (DINOC) results in 58\% less risk of infection, a block of 1 hectare greater area reduces the risk by $10 \%$, whereas an increase in planting density such as an addition of 500 trees per hectare reduces the risk by $43 \%$. The effect of distance to the nearest previously detected symptomatic tree was even stronger with $40 \%$ less risk of becoming symptomatic with an increase in distance of only $10 \mathrm{~m}$, which corresponds to two to five trees in the direction of the rows and one or two trees in the across-row direction. The estimated survival curves based on the fitted model for the entire time period are shown in Figure 2 for various values of covariates DINOC (Fig. 2A and B), AREA $^{2}$ (Fig. 2C and D), and DENS (Fig. 2E and F) with two hypothetical constant values of DIST over time $(6$ and $20 \mathrm{~m})$. Figure 3 illustrates the impact of varying values over time of nearestneighbor distance to previously detected symptomatic trees on survival curves.

Spatial patterns of disease. More details about the observed distance to the nearest previously detected symptomatic trees are shown in Table 6. The analysis confirmed that new symptomatic trees detected each year were generally located within short distances to previously detected ones; $50 \%$ or more of the new symptomatic trees were located within $6 \mathrm{~m}$ (greater distance between two contiguous trees in the across-row direction) of previously symptomatic ones, whereas 70 to $100 \%$ were located within $12 \mathrm{~m}$. More distant infections were generally very limited.

\section{DISCUSSION}

Control measures targeting Sharka disease have been applied in peach orchards of Southern France during the last 10 years. In this study, we used an exploratory approach to better understand

TABLE 5. Estimated $\beta$ coefficients, hazard ratio, and confidence limits for significant covariates in the final extended Cox survival model describing time to infection of trees by Plum pox virus strain M in peach orchards in Southern France

\begin{tabular}{lcccc}
\hline Covariate & Estimated $\beta$ & Hazard ratio & $\begin{array}{c}95 \% \text { con- } \\
\text { fidence limits }\end{array}$ & $P^{\text {a }}$ \\
\hline DINOC & -0.0087 & 0.991 & $0.987-0.995$ & $<0.0001$ \\
DIST & -0.0909 & 0.913 & $0.885-0.942$ & $<0.0001$ \\
AREA $^{2}$ & -0.1083 & 0.897 & $0.823-0.978$ & 0.0140 \\
DENS & -0.0011 & 0.999 & $0.998-1.000$ & 0.0013 \\
\hline
\end{tabular}

a $P$ values correspond to the univariate Wald statistics for significance of individual parameters. 
the factors affecting the spread of Sharka disease related to PPV$\mathrm{M}$ under conditions of roguing control as currently applied in France. Survival analysis was particularly powerful for exploring and quantifying the effects of tree location, peach orchard attrib- utes, and disease status in the vicinity of the orchards on peach tree infection risk. Modeling results generated useful information that can help to revise survey and removal strategies for improved Sharka disease control in orchards.
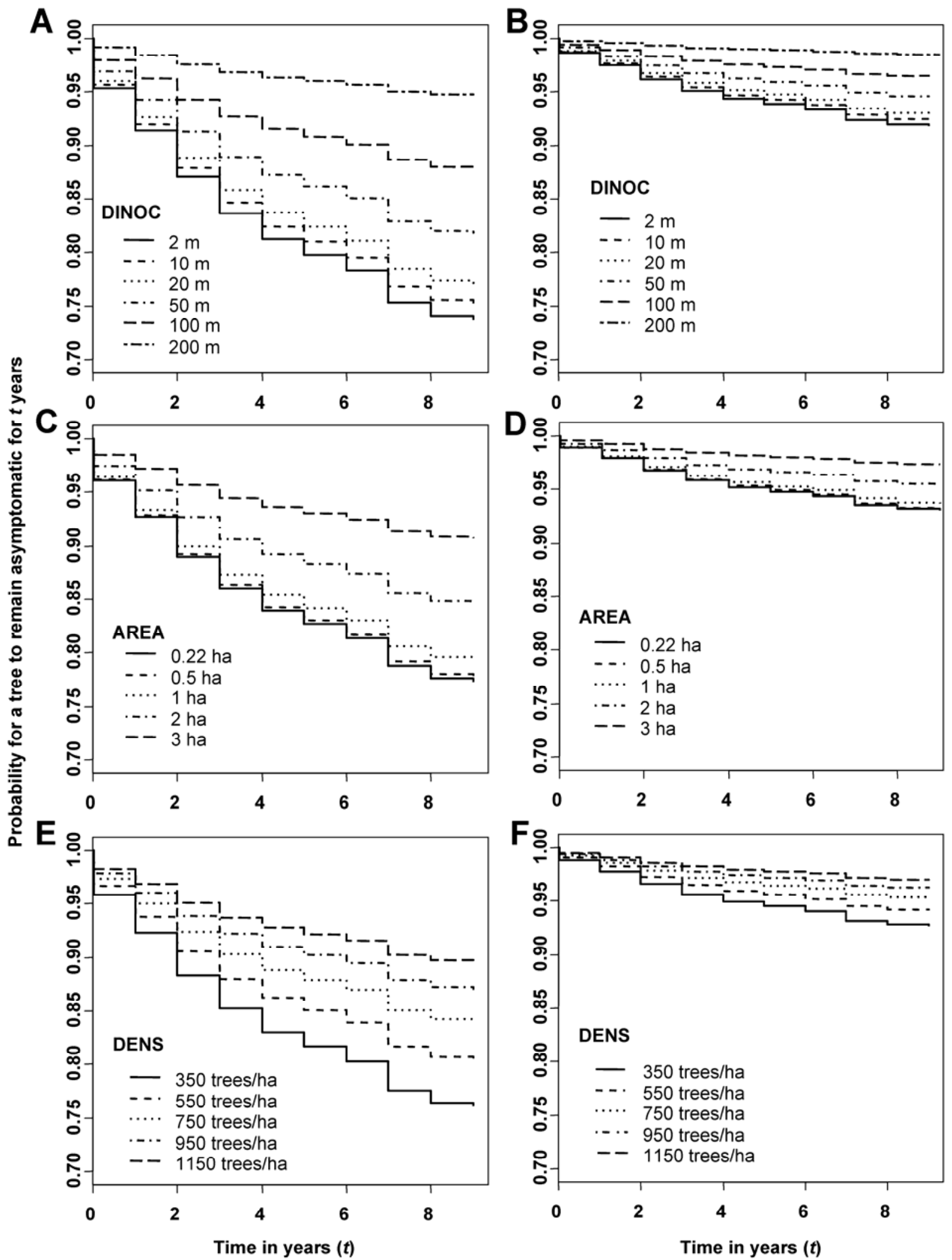

Time in years $(t)$

Fig. 2. Adjusted tree survival curves relative to time to infection by Plum pox virus strain $\mathrm{M}$ based on the fitted extended Cox survival model for two constant values of the distance to the nearest previously detected symptomatic tree: $6 \mathrm{~m}(\mathbf{A}, \mathbf{C}$, and $\mathbf{E})$ and $20 \mathrm{~m}(\mathbf{B}, \mathbf{D}$, and $\mathbf{F})$. A and $\mathbf{B}$ show the effect, on the probability for a tree to remain asymptomatic for $t$ years, of various values of the distance to the edge of the orchard block sharing a boundary with another infected orchard (DINOC) while the other covariates are kept at their median values. Adjusted survival curves were computed similarly in $\mathbf{C}$ and $\mathbf{D}$ for the covariate AREA ${ }^{2}$ (simulated for various values of the area of the blocks) and in $\mathbf{E}$ and $\mathbf{F}$ for various densities of planting (DENS). 
The low disease incidence in the orchards selected in the first year of surveying $(<1 \%$ for most of the blocks) was not necessarily representative of what was observed in other peach orchards during the same time period (i.e., early 1990s) in Southern France, when extensive surveys and control measures targeting the PPV-M strain were just starting. Peach orchards with higher disease incidence (10 to $20 \%$ ) were generally completely removed after only 1 to 3 years because annual roguing of symptomatic trees was not considered likely to succeed. Thus, these orchards were not included in this study. The opposite was also true. Some orchard blocks had an extremely low disease incidence (very few symptomatic trees) at disease discovery and no further postroguing infections were detected, although this latter situation represents very few cases in the extensive data set available from the eradication program surveys.
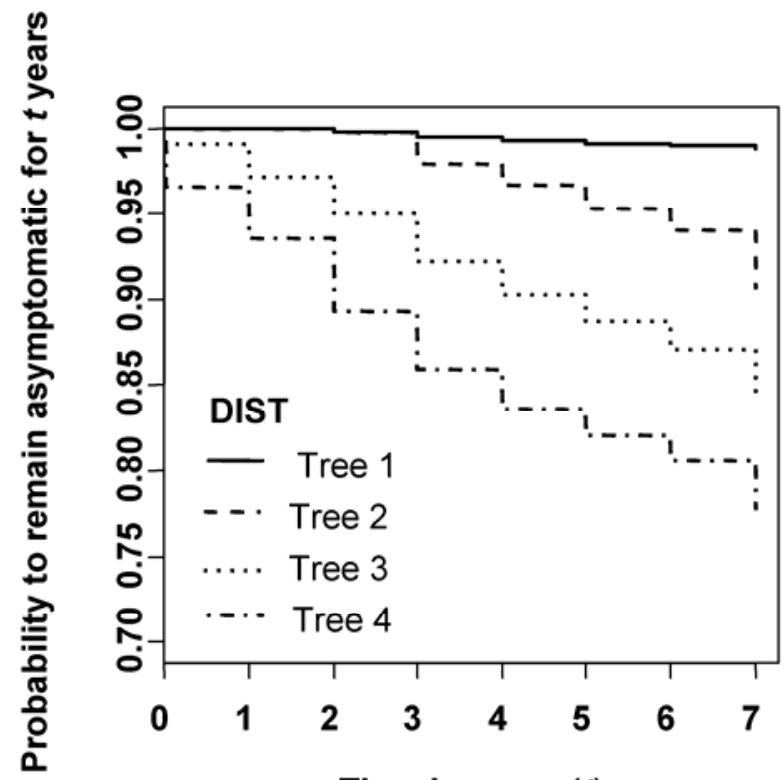

\section{Time in years $(t)$}

Fig. 3. Adjusted survival curves relative to time to infection by Plum pox virus strain $\mathrm{M}$ for four hypothetical trees located at variable distances to the nearest previously detected symptomatic tree (DIST) over time. Adjusted survival curves were based on the fitted extended Cox survival model using the median values of covariates DINOC (distance to the edge of the orchard block sharing a boundary with another infected orchard), AREA $^{2}$ (square of the area of the blocks), and DENS (densities of planting). Annual values of DIST during an 8-year period are specified as follows for four hypothetical trees: Tree 1: 55, 55, 40, 30, 30, 30, 30, and $30 \mathrm{~m}$; Tree 2: 55, 55, 40, 10, 10, 5, 5, and $2 \mathrm{~m}$; Tree $3: 20,10,10,5,5,2,2$, and $2 \mathrm{~m}$; and Tree $4: 5,5,2,2,2,2,2$, and $2 \mathrm{~m}$.
Disease related to the PPV-M strain spreads rapidly when no control measures are applied, and $100 \%$ disease incidence is often reached in less than 5 years $(1,44)$. This study indicates that disease control based on removal of symptomatic trees is clearly an effective method to slow epidemic development. However, in most of the blocks studied, new symptomatic trees were discovered every year until the end of the survey period, suggesting that sources of inoculum were still present in orchard blocks or in the vicinity.

Factors affecting the spread of Sharka disease in such conditions of control were explored using a Cox survival modeling approach. This semiparametric model was particularly appropriate for the available data set originating from survey results because of its robustness and its ability to take into account censoring (36). Indeed, there was a very high proportion of censored observations in the data set (e.g., a large number of trees were not diseased by the end of the study period due to control measures), which potentially reduced the power of the analysis. There were some potential difficulties due to the peculiarities of the available data set. The relatively low number of different orchards available for analysis in the survey data prevented control of orchard block characteristics, and consequently, the categories of the categorical covariates were not always well balanced (e.g., cultivar maturity). On the other hand, collinearity among the covariates, which could have potentially increased the variance of parameter estimates, was low despite obvious geometric relationships among some covariates (e.g., DINOC and $\mathrm{AREA}^{2}$ ). Inflation in variance parameter values due to correlation between covariates was estimated by the variance inflation factor $\left(\mathrm{VIF}=1 / 1-r^{2}\right.$ ) as described by Harrell (16). The values obtained were very limited for significant covariates. The highest correlation was between AREA $^{2}$ and DENS $\left(r^{2}=0.213\right)$, but the potential for resulting inflation in variance parameter estimates was limited $(+27 \%)$.

Under conditions of disease control, the risk of infection for a tree results from two overlapping processes. The first process is related to the intrinsic ability of the PPV-M strain to disseminate as a result of complex interactions between the various sources of inoculum within or in the vicinity of the blocks, the aphid populations, and the host peach trees. The second process is related to the impact of roguing measures, the ability of the inspectors to detect symptomatic trees in a particular block, as well as the quality of the removal procedures (i.e., the time elapsed between detection and removal of a symptomatic tree). Thus, our modeling results reflect the significant effects of factors related to both processes.

The best-fitting model showed that the risk for a tree to become infected through time is strongly influenced by the characteristics of the orchard block, the disease-related features in the vicinity, and the specific spatiotemporal processes of disease spread within

TABLE 6. Nearest-neighbor distance from newly identified peach trees symptomatic for infection by Plum pox virus strain M (PPV-M) to previously detected ones

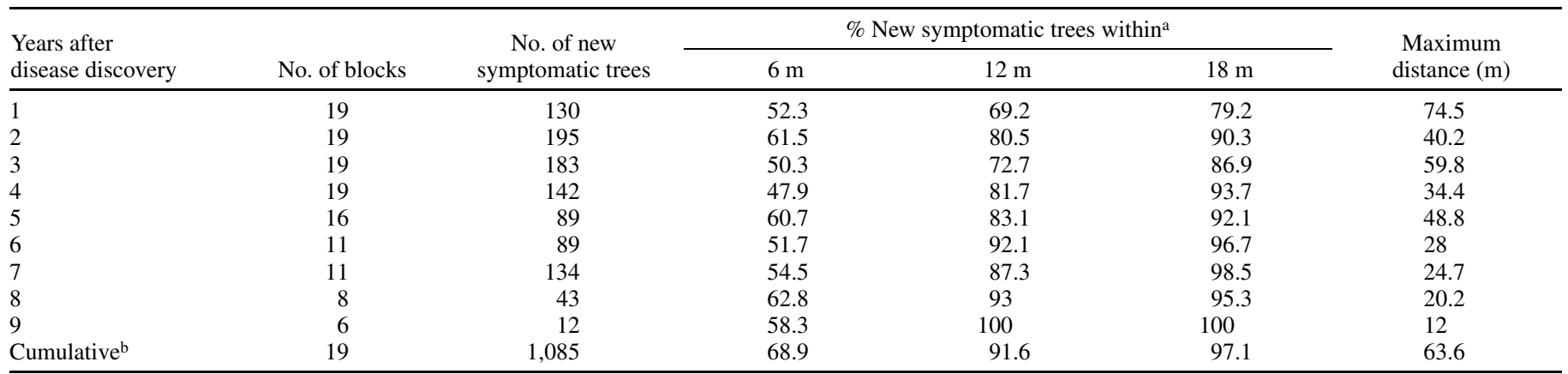

a Distances from each newly detected PPV-M symptomatic tree to previously detected ones were calculated for each year and each block separately and results were then pooled. Distances were parsed into consecutive 6-m distance categories.

${ }^{\mathrm{b}}$ Nearest-neighbor distances between all detected symptomatic trees during the entire survey period (including year of discovery) were calculated for each block separately, pooled, and parsed into consecutive 6-m distance categories. 
the block. Among the descriptors of peach blocks, the square of the area of the orchard blocks and the density of planting are both significant in the model and inversely associated with increasing disease incidence. The effect of block area likely reflects the fact that there were higher numbers of trees in the largest blocks, and consequently, a smaller proportion of diseased trees, even though the absolute number of symptomatic trees was generally greater in the largest blocks. Large blocks are also generally less vulnerable than smaller ones because the perimeter-to-area ratio is lower, and consequently, the plants in the center of the orchard block are at much less risk from diseased adjacent crops $(38,42)$. Density of planting, especially row spacing, alters the number of aphid landings and thus primary virus introductions in herbaceous annual crops $(7,20)$, but the effect in perennial tree crops is poorly documented. An orchard with a very closed canopy may be unattractive to aphid immigrants, consequently reducing the possibility not only of virus introductions from exogenous sources of inoculum but also of secondary disease spread within the orchard. This effect is probably stronger for nonpersistent viruses like PPV for which the rapidity of epidemic development is related to the abundance of itinerant alate migrants and to the frequency of vector movements (39). Density of planting probably has indirect effects as well. The physical structure of an orchard can strongly reduce wind speed within an orchard block and consequently affect aphid flight behavior (G. Labonne, unpublished data). The resulting pattern of disease may be modified; more intense aggregation of diseased trees should occur with a higher density of planting. The spatial analyses performed on each orchard block individually were consistent with this hypothesis in that significant disease aggregation was generally associated with higher density of planting (data not shown). Because aggregated symptomatic trees were probably more easily detected by the inspectors than dispersed diseased trees, it may be hypothesized that the number of missed infections was smaller in orchards with a higher density of trees, consequently reducing the secondary spread of the disease.

Disease dissemination between orchards is known to occur frequently in PPV epidemics $(15,27,44)$. The best-fitting model did not provide direct evidence for the influence of exogenous sources of inoculum when examining the number of susceptible and infected Prunus orchards contiguous to the studied peach blocks (both variables were not significant predictors of tree infection at $P=0.05$ ). A more accurate quantification of the inoculum pressure in the vicinity of the orchard blocks probably would have improved the model. Because the exact number of infected trees found in the vicinity each year of the survey period was not always available for all blocks, this factor could not be investigated directly. The presence of windbreaks and their orientation in relation to the dominant wind and contiguous infected orchard blocks, which could have prevented or reduced the number of virus introductions, were not significant either. This nonsignificance can be explained by the fact that the height and density of windbreaks (cypress or a mix of cypress and poplar) and consequently the level of protection against aphid flights varied with time and from one orchard block to another. However, the influence of exogenous sources of inoculum on disease development within the peach blocks was demonstrated indirectly when we considered locations of diseased trees toward the edge of the block contiguous to another PPV-affected orchard. This descriptor (DINOC) was highly significant in the best-fitting model, suggesting that scattered infections in the form of shallow gradients or edge effects might be present in some of the blocks studied. Based on model predictions, the risk of infection decreases quickly with increased distance from the edge of the orchard block, and a tree located more than $100 \mathrm{~m}$ away has very low risk of infection.

The influence of endogenous sources of PPV inoculum was also clearly supported by the extended Cox model. The variable describing the distance to the nearest previously detected symptomatic tree was highly significant when it was incorporated in the model as a time-dependent covariate. Model predictions as well as observed values suggested that the disease status of an infected tree likely influenced the disease status of its neighbors. Examination of individual maps of cumulative disease also indicated that diseased trees were mostly aggregated within the peach orchards studied. Such spatial pattern of cumulated disease has been observed in a previous study focusing on peach orchards of Southern France infected by the PPV-M strain, but not subjected to roguing (12). Spatial analyses performed on each peach block subjected to roguing using the same methods as in the previous study (12) brought similar results of disease aggregation (data not shown) and therefore strongly argue for the occurrence of a secondary spread of disease. Most of these transmission events probably occurred after the roguing procedures started. There are several pieces of evidence to support this hypothesis. First, variable latent periods are known to occur with PPV, but it is unlikely that they exceed 3 years, especially in commercial-irrigated peach orchards. Second, the covariate measuring the distance of all new infected trees to those detected the first year of survey was a poor predictor of the risk for a tree to become infected (data not shown). Only the time-dependent form of this covariate (i.e., the covariate measuring the distance of new infected trees to the ones detected in the preceding years) was highly significant. Third, the assumption of time independence of the covariates in the Cox model was verified only after the second year of survey, which indicates that infections that occurred before and after this date did not originate from the same process.

Thus, modeling results indicated that PPV infections within peach orchards subjected to roguing were likely to originate from a combined impact of exogenous sources of inoculum, the ending of latent infections, as well as missed infectious trees or delayed removal. The relative influence of these three factors varied from one orchard to another, depending on orchard characteristics and the inoculum pressure within and outside the orchard blocks.

The results of this study clearly demonstrated that the control method of yearly removals of symptomatic trees from peach orchards infected by the aggressive PPV-M strain considerably slowed disease spread but did not achieve complete eradication. These findings are in accordance with that observed in the past for other viral diseases of perennial crops subjected to roguing procedures $(2,3,40,41)$. They are also in agreement with deterministic modeling approaches that have shown that the intensity of roguing of diseased plants has a strong influence on disease persistence $(9,19)$.

In the early 1990s, numerous foci of PPV-M were detected in Southern France and were widespread in an agrosystem often characterized by relatively small orchards and fragmented cropping areas. Complete eradication was not realistic nor attempted because it would require much more drastic numbers of tree removals. Therefore, the strategy chosen was to limit disease incidence in restricted areas. Consequently, prevalence of PPV-M in orchards has been considerably reduced in most regions of Southern France where continuous disease control is applied. With decreasing PPV-M incidence in orchards in these regions and the increasing use of certified virus-free plant material, disease dispersal between nearby or more distant orchards is less likely to occur now than 10 years ago. However, better detection and removal of internal sources of inoculum are needed before considering a scaling-down of the systematic multiyear surveys in the PPV-M foci subjected to disease control for several years. This could probably be achieved by roguing asymptomatic trees in the proximity of symptomatic ones. Roguing within 12 to $18 \mathrm{~m}$ of a symptomatic tree would probably be a safe measure to capture most latent infections and infectious but asymptomatic trees when disease incidence is low. However, such severe measures might be economically unacceptable in some small orchards and might 
only be practical as a final clean-up of an area with very low disease incidence. The exact spatiotemporal process of disease spread within each orchard block was not analyzed in detail due to the low number of new annual infections, the removal of infectious trees each year, and the likely occurrence of latent periods of variable duration. Therefore, further investigation is needed to adequately estimate the number of trees that must be removed in specific orchards or cropping areas to effectively achieve eradication. Moreover, because the removal of asymptomatic plants can be unpopular and therefore difficult to apply, switching visual inspections for serological testing coupled with appropriate sampling procedures would be an alternative to improve detection of infectious but presymptomatic or asymptomatic trees, especially in low-incidence areas where detecting the last vestiges of disease is problematic.

In this study, we showed that survival analysis is a powerful and robust method for exploring and analyzing survey data in botanical epidemiology. The approach will be further developed to investigate risk factors associated with Sharka disease invasion at a regional scale.

\section{ACKNOWLEDGMENTS}

We thank G. Clauzel from the INRA Experimental Station of Gotheron for collecting and providing the survey data from the Drôme region; the Fédération Régionale de Défense contre les Organismes Nuisibles (FREDON) of Provence Alpes Cote-d'Azur (PACA) and LanguedocRoussillon (LR), their sections of Gard and Pyrénées-Orientales and the Service Régional de la Protection des Végétaux PACA and LR for collection of the data and their help in the selection of plots of interest; and the USDA APHIS-PPQ for providing support for this project.

\section{LITERATURE CITED}

1. Adamolle, C., Boeglin, M., Labonne, G., Candresse, T., and Quiot, J. B. 1994. Une souche nécrogène du Plum pox potyvirus provoque un dépérissement sur certains cultivars de pêcher. EPPO Bull. 24:721-730.

2. Allen, R. N. 1978. Epidemiological factors influencing the success of roguing for the control of bunchy top disease of bananas in New South Wales. Aust. J. Agric. Res. 29:535-544.

3. Allen, R. N. 1987. Further studies of epidemiological factors influencing control of Banana bunchy top disease and evaluation of control measures by computer. Aust. J. Agric. Res. 38:373-382.

4. Avinent, L., Hermoso de Mendoza, A., and Llácer, G. 1993. Comparison of sampling methods to evaluate aphid populations (Homoptera, Aphinidea) alighting on apricot trees. Agronomie 13:609-613.

5. Bar-Joseph, M., Roistacher, C. N., and Garnsey, S. M. 1983. The epidemiology and control of Citrus tristeza disease. Pages 61-72 in: Plant Virus Epidemiology: The Spread and Control of Insect Borne Viruses. R. T. Plumb and J. M. Thresh, eds. Blackwell Scientific Publications, Oxford, UK.

6. Bousalem, M., Candresse, T., Quiot-Douine, L., and Quiot, J. B. 1994. Comparison of three methods for assessing Plum pox virus variability: Further evidence for the existence of two major groups of isolates. J. Phytopathol. 142:163-172.

7. Burdon, J. J., and Chilvers, G. A. 1982. Host density as a factor in plant disease ecology. Annu. Rev. Phytopathol. 20:143-166.

8. Campbell, C. L., and Madden, L. V. 1990. Introduction to Plant Disease Epidemiology. John Wiley \& Sons, New York.

9. Chan, M. S., and Jeger, M. J. 1994. An analytical model of plant virus disease dynamics with roguing and replanting. J. Appl. Ecol. 31:413-427.

10. Cox, D. R. 1972. Regression models and life tables (with discussion). J. R. Stat. Soc. B. 34:187-220.

11. Crescenzi, A., d'Aquino, L., Comes, S., Nuzzaci, M., Piazzolla, P., Boscia, D., and Hadidi, A. 1997. Characterization of the sweet cherry isolate of plum pox potyvirus. Plant Dis. 81:711-714.

12. Dallot, S., Gottwald, T., Labonne, G., and Quiot, J.-B. 2003. Spatial pattern analysis of Sharka disease (Plum pox virus strain M) in peach orchards of Southern France. Phytopathology 93:1543-1552.

13. Dallot, S., Labonne, G., Quiot-Douine, L., Boeglin, M., Candresse, T., and Quiot, J. B. 1998. Peculiar plum pox potyvirus D-populations are epidemic in peach trees. Acta Hortic. 472:355-365.

14. Giauque, P., and Hilaire, C. 2003. Le Pêcher. CTIFL, Paris.

15. Gottwald, T. R., Avinent, L., Llacer, G., Hermoso de Mendosa, A., and Cambra, M. 1995. Analysis of the spatial spread of Sharka (Plum pox virus) in apricot and peach orchards in eastern Spain. Plant Dis. 79: 266-278.

16. Harrell, F. E. 2001. Regression Modeling Strategies. Springer VerlagSpringer Series in Statistics, New York.

17. Hosmer, D. W., and Lemeshow, S. 1999. Applied Survival Analysis: Regression Modeling of Time to Event Data. John Wiley \& Sons, New York.

18. Ihaka, R., and Gentleman, R. 1996. R: A language for data analysis and graphics. J. Comput. Graph Stat. 5:299-314.

19. Jeger, M. J., and Chan, M. S. 1995. Theoretical aspects of epidemics: Uses of analytical models to make strategic management decisions. Can. J. Plant Pathol. 17:109-114.

20. Jones, R. A. C. 1994. Effect of mulching with cereal straw and row spacing on spread of bean yellow mosaic potyvirus into narrow-leafed lupins (Lupinus angustifolius). Ann. Appl. Biol. 124:45-58.

21. Jules, E. S., Kauffman, M. J., Ritts, W. D., and Carroll, A. L. 2002. Spread of an invasive pathogen over a variable landscape: A nonnative root rot on Port Orford cedar. Ecology 83:3167-3181.

22. Kranz, J. 2003. Comparative Epidemiology of Plant Diseases. SpringerVerlag, Berlin.

23. Labonne, G., Lauriaut, F., Yvon, M., Quiot, J. B., Avinent, L., and Llacer, G. 1995. Aphids as potential vectors of Plum pox virus: Comparison of methods of testing and epidemiological consequences. Acta Hortic. 386:207-218.

24. Labonne, G., Yvon, M., and Quiot, J. B. 1994. Dissemination du Plum pox virus par les pucerons: Analyse des vecteurs potentiels du virus dans un verger d'abricotiers. EPPO Bull. 24:681-690.

25. Levy, L., Damsteegt, V., and Welliver, R. 2000. First report of Plum pox virus (Sharka disease) in Prunus persica in the United States. Plant Dis. 84:202.

26. Mora-Aguilera, G., Nieto-Angel, D., Campbell, C. L., Teliz, D., and Garcia, E. 1996. Multivariate comparison of papaya ringspot epidemics. Phytopathology 86:70-78.

27. Morvan, G. 1988. The epidemiology of Plum pox virus in the apricot orchards of southern France: Description of computer tools and main observations. Acta Hortic. 235:263-270.

28. Myrta, A., Boscia, D., Potere, O., Kolber, M., Nemeth, M., Di Terlizzi, B., Cambra, M., and Savino, V. 2001. Existence of two serological subclusters of Plum pox virus, strain M. Eur. J. Plant Pathol. 107:845-848.

29. Nemchinov, L., and Hadidi, A. 1996. Characterization of the sour cherry strain of Plum pox virus. Phytopathology 86:575-580.

30. Nemchinov, L., Hadidi, A., Maiss, E., Cambra, M., Candresse, T., Damsteegt, V. 1996. Sour cherry strain of Plum pox potyvirus (PPV): Molecular and serological evidence for a new subgroup of PPV strains. Phytopathology 86:1215-1221.

31. Quiot, J. B., Labonne, G., Boeglin, M., Adamolle, C., Renaud, L. Y., and Candresse, T. 1995. Behavior of two isolates of Plum pox virus inoculated on peach and apricot trees: First results. Acta Hortic. 386:290-297.

32. Rowlingson, B. S., and Diggle, P. J. 1993. SPLANCS: Spatial point pattern analysis code in S-plus. Comput. Geosci. 19:627-655.

33. Roy, A. S., and Smith, I. M. 1994. Plum pox situation in Europe. EPPO Bull. 24:515-523.

34. Scherm, H., and Ojiambo, P. S. 2004. Applications of survival analysis in botanical epidemiology. Phytopathology 94:1022-1026.

35. Smith, I. E., Candresse, T., and Dosba, F. 1994. La Sharka: Où en est-on en Europe et ailleurs? L'Arboriculture Fruitiere 471:29-34.

36. Therneau, T., and Grambsch, P. M. 2000. Modeling Survival DataExtending the Cox Model. Springer-Verlag, New York.

37. Therneau, T., and Lumley, T. 2003. The Survival Package R. http://www.cran.r-project.org. Published online by The Comprehensive R Archive Network.

38. Thresh, J. M. 1982. Cropping practices and virus spread. Annu. Rev. Phytopathol. 20:193-218.

39. Thresh, J. M. 1985. Plant virus dispersal. Pages 51-101 in: The Movement and Dispersal of Agriculturally Important Biotic Agents. D. R. MacKenzie, C. S. Barfield, G. G. Kennedy, R. D. Berger, and D. J. Taranto, eds. Claitor's Publishing Division, Baton Rouge, LA.

40. Thresh, J. M. 1988. Eradication as a virus disease control measure. Pages 155-194 in: Control of Plant Diseases: Costs and Benefits. B. C. Clifford and E. Lester, eds. Blackwell Scientific Publications, Oxford, UK.

41. Thresh, J. M., and Owusu, G. K. 1986. The control of cocoa swollen shoot disease in Ghana: An evaluation of eradication procedures. Crop Prot. 5:41-52.

42. Vanderplank, J. E. 1948. The relation between the size of fields and the spread of plant disease into them. Part I. Crowd diseases. Empire. J. Exp. Agric. 16:134-142.

43. Vanderplank, J. E. 1963. Plant Diseases: Epidemics and Control. Academic Press, New York.

44. Varveri, C., Zintzaras, E., Dimou, D., and Di Terlizzi, B. 2001. Monitoring and spatiotemporal analysis of PPV-M spread in two apricot orchards in southern Greece. Acta Hortic. 550:129-133. 